\title{
Discourses of transnormativity in vloggers' identity construction
}

\author{
Lucy Jones, University of Nottingham
}

\begin{abstract}
This paper investigates the construction of two transgender vlogger personas, providing insight into the prevalence of normative discourses which may be drawn on when constructing transgender identities. Many transgender people around the world rely on the internet as a source of information and guidance, with online video diaries ('vlogs'), in which young people record and chart their experiences of transition, playing a particularly important role. In this paper, discourse from two popular transgender vloggers is critically analysed. It is found that the vloggers index identities which are broadly in line with what Zimman (2012) terms the archetypal 'true transsexual', an ideological model of what it means to be 'authentically' transgender. This corresponds with heteronormative, essentialist expectations of binary gender. The vloggers are shown to authenticate their own experiences by stating what is 'typical' and positioning themselves as 'experts'. Ultimately, it is argued that the version of transgender identity and experience that they put forward reproduces prevalent discourses of normative gender and sexuality.
\end{abstract}

Keywords: transgender; transnormativity; identity construction; heteronormativity; vlogs

\section{Introduction}

In this paper, I consider the prevalence of normative discourses to the identity construction of young transgender people. Transgender youth - those whose gender identity does not match that assigned to them at birth - are a particularly vulnerable group in society. They may require compassion and specialist support in both understanding their gender identity, and making decisions regarding their transition. However, Holman and Goldberg (2006: 97) argue that many young transgender people are unable to initially articulate their feelings because information is not always readily available to them. In the UK, there are growing numbers of youth groups being set up specifically for transgender young people, and more and more National Health Service organisations now provide information and support. For many young people, though, this is difficult to access without the permission or assistance of their families. As Grossman and D'Augelli (2006: 113) argue, young people who are transgender are at an increased risk of becoming socially excluded and isolated because they are less likely than transgender adults to be able to gain access to suitable support services.

For this reason, the internet acts as a source of information and guidance for many. Online video diaries, in which (typically young) transgender people record and chart their experiences of transition, play a particularly important role. Video logs (or 'vlogs') are growing in popularity with young people around the world, and YouTube ${ }^{1}$ is a primary

\footnotetext{
1 YouTube.com was established in 2005 as a site for sharing short videos, and is now accessed by more than one billion users around the world (YouTube 2015).
} 
platform for them. Vlogs often take the form of diaries but, like written blogs, they can also be intended to share particular information, advice, or stories. Many young trans people in particular have turned to YouTube to document their experiences, often making videos where, as Raun (2015: 368) puts it, 'they list their current physical changes and current state of mind. They track and archive transition as a bodily and psychosocial process or they "check in" to signal that they are still there, sometimes without having anything in particular to say'. Transgender autobiographies have long played an important role for trans people, as they allow a 'voyage into the self' (Prosser 1998: 115). Vlogs, however, by their very public nature, also enable the young people creating videos to 'affirm their bodies and selves, in the process generating far-flung communities of support' (Horak 2014: 573). This can lead to clichéd and homogenized representations, with young amateur broadcasters following a seemingly fixed approach to both creating and editing a transition diary. Nevertheless, they give an independent voice to anybody with access to the internet. This means that messages about being transgender can bypass mainstream broadcast media and thus are unfiltered according to capitalist or populist agendas (ibid.). For young people who may have experienced hostility and rejection due to their trans identity, then, vlogs allow the construction of their own sense of legitimacy and normativity.

In this paper, I analyse discourse from two of the most popular and influential transgender vloggers on YouTube. In the spirit of critical discourse analysis, I view the vlogs as potentially powerful in terms of how subjectivities are constituted, and how boundaries between what is legitimate and inauthentic are constructed (cf. Jørgensen and Phillips 2002, Fairclough 1989). However, unlike the institutional or corporate texts usually analysed using critical discourse analysis, these vlogs typically emerge from the bedrooms of young amateurs with simple webcam technology. I do not, then, critically analyse them as cynically pushing certain ideological or political agendas. Instead, I include them here in order to uncover the prevalent discourses that young people may draw on in constructing and performing personas relevant to their role as transgender vloggers. As I will argue below, the young people in these vlogs authenticate their own experiences by stating what is 'typical' and - as also found by Dame (2013) - by positioning themselves as 'experts'. This 'typical' transgender identity relies, in this data, on prevalent discourses of binary gender and normative heterosexuality. To identify and critique these discourses, I draw on Bucholtz and Hall's (2005) sociocultural linguistic principle of Positionality, outlined below.

\section{Analytical approach}

Bucholtz and Hall (2005) present a series of principles which, they suggest, bring together findings within interactional sociolinguistics about how speakers produce identities through their talk. Of direct relevance to the current study is their principle of Positionality. This explains identity as achieved through the positioning of oneself and others, in relation to both local and global personas and identity categories. Bucholtz and Hall draw on theories of indexicality (Silverstein 2003, Ochs 1992) and performativity (Butler 1990) to explain how speakers produce culturally recognisable identities through their talk, taking into account local-level norms and broader ideologies. This conceptualisation of identity is particularly useful for analyses aiming to critically evaluate the discourses that speakers draw on in 
producing meaningful identities. For this reason, it has been implemented by those taking a queer linguistics approach (e.g. Morrish and Sauntson 2007, Jones 2012). Queer linguistics aims to challenge and uncover dominant cultural ideologies surrounding heterosexuality and binary gender which are often hidden or implicit within language use (see Motschenbacher \& Stegu 2013); I follow this approach here by critiquing the normative assumptions that are implicit in vloggers' talk.

Sociolinguistic analyses of transgender people's language use have thus far focused on the terminology and labels used to talk about trans people (Valentine 2007), the use of gendered grammar to index different gendered subjectivities (Borba and Ostermann 2007, Kulick 1996, Hall 1997, Hall and O'Donovan 1996), the sociophonetic realisation of 'masculine' or 'feminine' speech styles in trans men (Zimman 2012), and coming out as transgender (Edelman 2009, Zimman 2009). Studies such as these reveal that the discourse of trans people may reveal broader ideological structures of gender and sexuality which both constrain and facilitate the construction of (trans)gender identity. These structures, I argue, are largely heteronormative, dictating the binaries of gender and sexuality by which many people abide: one is female or male, gay or straight, transgender or cisgender ${ }^{2}$. Indeed, an essentialist view of gender and its apparently static relationship to the body may position being transgender not as an identity, but as a physical 'sex change'. Yet, as Zimman (2014: 21) shows, the body is not always a requisite for gender expression. His analysis of online forums for trans men, for example, shows that normatively 'male' body parts may be referred to symbolically or metaphorically by trans men who have not had surgery. In this way, trans people can subvert essentialist assumptions about the 'natural relationship' between the body and gender and, therefore, authenticate their own identities outside of heteronormative structures.

It is also the case, however, that the institutional and cultural structures which reproduce gender ideologies often render trans people as 'other' (Edelman 2009). As a result, Zimman (2012: 12) argues, there is an expectation for those who are transgender to authenticate themselves in line with a normative ideal: the archetypal 'true transsexual', promoted historically by pathologists and psychiatrists. What is ideologically expected to be 'typical' for trans people includes: having always known that one was in the 'wrong body'; having what are recognised as homosexual desires before coming out as trans, and heterosexual ones afterwards; and striving for surgical and hormonal treatments leading to a normatively female or male body (ibid). Variations on this ideal (such as trans people who do not have surgery, or who are lesbian, gay or bisexual) do not fit with a cultural discourse which is defined by the understanding of transsexualism as pathology. Whilst many trans people will identify strongly with a normative script, those who do not align with it may feel marginalised or inauthentic due to its prominence. The data considered in this paper reveals the potential salience of such 'transnormative' discourse, looking specifically at its relevance to young transgender people making YouTube videos. A discussion of the methodology involved in this study is provided below.

\footnotetext{
${ }^{2}$ Cisgender individuals identify with the gender assigned to them at birth.
} 


\section{Data}

There are a considerable number of vlogs in which transgender people report their experiences throughout their transition. A YouTube search for 'transgender diary', for example, produces more than 144,000 videos at the time of writing. The vast majority of these vlogs come from young people in their late teens and early twenties, most of whom are based in the USA. Below, I consider just two of these young people, a trans man and a trans woman, allowing for close discourse analysis. I selected the two vloggers based on their popularity (in terms of the number of subscribers that that they each have to their YouTube channel) and influence (measured by the number of times that their videos have been watched). In 2014, when this data was collected, each vlogger had more than 10,000 subscribers, and their most popular videos had been viewed more than 100,000 times. My data selection was based on videos where the vloggers talked in monologue only, and on videos which had the biggest impact (those within the top $25 \%$ of viewing figures for each YouTuber). Extracts from some of these videos are transcribed ${ }^{3}$ below; these extracts have been selected as a result of my research aims, in that they include the discourses I have been seeking to identify. I cannot - and do not - claim that the language and identity work outlined here represents that of the entire body of videos uploaded by each vlogger. To gain a truly representative insight into the discourse of these vlogs and thus check that the discourses outlined below do run throughout them, a corpus linguistics approach could be used (see Baker 2014). Instead, the aim of this analysis is to provide evidence of the existence of transnormative discourse with a view to further research in this area.

Similarly, though a person of each gender has been selected here, it is not my intention to directly compare the discourse used within the vlogs. It is also not my intention to present these two vloggers as somehow representative of all trans men or trans women, or indeed to homogenise 'the' transgender identity. After all, the nature of patriarchy, sexism, homophobia and essentialist ideologies of gender means that trans women and trans men experience very different forms of marginalisation in society. Instead, my aim here is to gain initial insight into the potential impact of transnormativity by analysing how two different and unconnected vloggers draw on this discourse to produce their personas.

The first vlogger is a young trans woman from New York State, of mixed racial heritage and aged between 17-19 in her videos. I call her Sophia in this paper. She is softly spoken, and wears fashionable, feminine clothes, accessories and makeup. The second is a trans man whose age in his uploaded videos spans 17-23. He is white and comes from Massachusetts. He wears clothes associated with hip-hop culture, such as baggy jeans and baseball caps, and I refer to him here by the pseudonym Jay. Socioeconomic information was not available to me, but both vloggers attended university and, on this basis, I categorise them as broadly middle-class. I have chosen to anonymise the data here because, although the videos are publicly available online, the young people may not have considered their potential reach. The young people may also be potentially vulnerable and, as such, it is appropriate to protect their identities through the use of pseudonyms.

\footnotetext{
${ }^{3}$ I am grateful to Lisa Lehnen for her transcription of these extracts.
} 
As argued by Dame, transgender vloggers find themselves in an unusual position: typically, they are young amateur filmmakers, creating videos with basic webcam technology, yet they are also often perceived by their viewers to be experts (2013: 46). As Horak outlines, trans vlogs tend to have certain formal qualities - 'close framing, a private setting, direct address, and amateur style' — which make the person seem 'real and their statements true' (2014: 575). This results in viewers feeling as though they know the vlogger personally. Very popular YouTubers like Sophia and Jay also fill a gap in terms of media representation of everyday trans experience. Because their videos receive high numbers of views, they play a potentially important role in communicating ideological perspectives to other young transgender people. Below, extracts from Sophia's and Jay's videos are discussed in relation to discourses of 'transnormativity', outlined earlier, and the construction of a trans vlogger persona.

\section{Analysis}

\subsection{Sophia}

Sophia's videos are often explicitly framed (in their titles and descriptions, as well as within the content itself) as 'how to' vlogs. She often begins by contextualizing her videos, stating that 'this video is about...'. In the vlog below, Sophia offers advice on how to tell a prospective partner of one's transgender status. She does not explicitly state whether this is based on her own experience, but frames the vlog as though it is:

\section{Extract 1}

1 this video is going to be: (.) telling you:r (1) mate. (.) your boyfriend? or girlfriend? whoever you

2 might be seeing that you are male to female. (.) female to males? you know that applies to you

3 too but (.) I'll talk from like uh my perspective being uh (.) male to female (.) so I hope you guys

4 enjoy. (.) so if you come out as trans. or you start your transition. (.) and your family does not

5 agree with it your family does not like that you're transitioning or you know whatever. (1) you

6 can get (.) very sad over this obviously you can get very depressed. (.) you: (.) will get

7 unmotivated (.) I completely understa:nd. why (.) when girls will wanna get in a relationship (.)

8 and they get to the point of being pretty and passable enough (.) to whe:re people don't know.

9 or people can't like automatically tell that they're transgender (1) I understand why the girls

10 do not wanna just come out and (.) tell a guy. (1) a fear of rejection. I mean nobody wants (.) you

11 know the guy who they think is (1.5) way attractive a guy that they think is (.) you know nice (.)

12 a guy who likes their personality. (.) you don't want that guy saying (.) oh you know you are a

13 man or (.) you're a transvestite or whatever? (.) you know (.) they'll say. (1) you want to have

14 that person in your life and so you don't wanna tell them that you're trans. (.) and when you get

15 to a point of being passable (.) a:nd you don't think that you're trans every day. I mean it

16 doesn't just come up (.) oh yeah (.) I was born a boy. (.) you know you just live your life. (.)

17 a:nd (.) you know you don't think about that types of stuff. (.) so it just doesn't (.) you know

18 come up right away.

Throughout this extract, Sophia addresses the viewer directly with the second-person pronoun 'you' (explicitly addressing the viewer in lines 2-3: 'this applies to you'; 'I hope you guys enjoy'). This clearly alludes to an interaction rather than a monologue (also seen by frequent use of the fillers 'you know'). Her expert persona is evident from her modality, through 
which she positions herself as being informed. For example, in lines 6-7 she states how the viewer will feel or what they can experience ('you can get very sad over this, obviously. You can get very depressed. You will get unmotivated'). For this reason, it is relevant to consider the norms Sophia puts forward, particularly in relation to sexuality. Though she initially frames a future 'mate' of a male to female trans person as either a boyfriend or a girlfriend (line 1), from line 10 onwards she refers to that potential partner as 'a guy'. Furthermore, it is telling that the 'girls' she refers to in lines 7 and 9 are not prefixed with 'straight' or 'heterosexual', and are instead unmarked for their sexuality. This logically positions the category of 'girls' as interested in 'guys', which serves to normalize relationships between trans women and all men, and excludes trans girls who may identify as lesbian or bisexual. In this sense, Sophia draws on and reproduces heteronormative assumptions in her vlog.

Also of interest in this extract is Sophia's description of what it takes to be 'passable' (line 8): 'when girls will wanna get in a relationship and they get to the point of being pretty and passable enough to where people don't know...'. The inclusion of 'pretty', here, is somewhat ambiguous - it is not clear whether Sophia is suggesting that prettiness is achieved through makeup, hormones, increased confidence over time, or surgery. It is apparent from her construction, though, that being pretty results from some sort of process ('when...they get to the point'). Sophia again draws on heteronormative notions, here, since 'pretty' is an adjective reserved most typically for women and girls, and connotes a very specific sort of attractiveness that is related to straight male desire and conventional femininity.

This also frames as normative and typical the idea that all transgender people wish to 'pass'. This may also be referred to as living in stealth, 'wherein one's trans history is not evident on a day-to-day basis' (Edelman 2009: 164). Not all trans people will choose to disclose their transgender status at all times but, due to heteronormative assumptions of binary, cisgender identity, many will have to 'out' themselves by disclosing their transgender status throughout their lives. Others, of course, may choose not to live in stealth, or may identify as non-binary, though Sophia leaves no space here for these individuals. The consequence of this is that she narrows the scope of what is acceptable or legitimate in terms of transgender identity for her viewers. By assuming that her viewers all share a particular perspective or experience, she is able to construct a sense of normative community identity. Of course, this is based on her own perception of what is typical, allowing her to authorize and legitimize her own identity in line with this construct.

Sophia's most popular videos feature her documenting her transition, as in the extract below. Here, she discusses changes that have occurred since being on hormones and, temporarily, having to stop taking them. She shows a concern to tell the truth about her bodily changes, even if she finds them embarrassing, indicating her perception of the vlogs as an important resource for those learning about gender transition. This extract again reveals how particular assumptions are transmitted and normalized in vlogs of this nature: 


\section{Extract 2}

1 another thing that was like torturing me absolutely torturing me (.) is my leg hair (1.5) so like it's

2 the summer. (.) and every girl wants to wear their short shorts and all that types of shit. (1)

3 a:nd (2.0) I would have to sha:ve. (1) every single day and then I would get stubble like six

4 hours later after I shaved. (.) and so: I'd have to like co:nstantly keep shaving my legs. and then

5 that constantly i:rritated my legs since then I got a whole bunch of ra:zor burn it was just (.) ugly

6 ugly ugly mess (.) and uhm (1.5) so that was (.) a horrible mess and already I noticed uhm (.)

7 after like eleven twelve days on hormones (.) I noticed tha:t. it's growing a little slower (1.5)

8 very. slower. like it'll (.) like I get I'll get stubble (.) the next day (.) instead of like (.) six hours

9 later but (.) it's good (.) because when you (.) you know shave and stuff like that and you are

10 out in the clu:b (.) o:r (1) you're (.) you know with your boyfrie:nd. or girlfriend or whatever (.)

11 and then. (1) I mean you shave and then later that night you're stubbly it's (.) I fucking hate

12 that (.) I really hate that excuse me. (1) u:hm (2) ya:h I think that's pretty much

13 it. (.) uhm (1) I feel like my boobs got smaller. (.) but I think that's just 'cause like (.) when you

14 first get on them you feel like you have like a D cup. (.) when your boobs start growing you're

15 so happy (.) and then after you like start getting used to them and everything it's like oh. (.) you

16 know they're not that special. (.) so I feel like (.) maybe it's tha:t? (.) that I was going through (.)

17 and maybe they didn't get smaller but. (.) I feel like they did so (.) so yeah (.) that's pretty much

18 tha:t (.) uhm (.) like (.) I think my face didn't get any less feminine. (.) uhm (.) like no body fat

19 (1) redistributed itself in a more ma:sculine fashion or (.) anything like that. oh. (.) <shows right

20 fist to camera> I started getting hair (.) \{@on my knuckles@\} (2) it's horrible to admit but (1)

21 it's the truth.

This extract highlights the salience of body hair as an ideological marker of gender; women are expected to be hairless, whereas hairy men are thought to be more masculine or virile. This is drawn on by Sophia in this video as she frames it as 'torture' (line 1) when she has particularly fast-growing leg hair and has to shave frequently; she uses pauses in lines 1-3 to emphasise her frustration with this fact ${ }^{4}$. Her leg hair is given agency in this construction, as the leg hair (the subject) is torturing her (the object). This allows her to position her body as acting against her will or control, disassociating herself from it. This construction is repeated in line 19, as she talks about her body fat redistributing itself. This indicates her concern to distance herself from culturally masculine signifiers such as body hair, or masculine muscle definition. Furthermore, she evaluates her body in line with ideals of femininity, referring to her legs as an 'ugly ugly ugly mess' (line 6) due to a rash, repeating the adjective 'ugly' to emphasise that it is unattractive to have blemishes or imperfections on one's skin. This is also apparent in line 10, when Sophia describes the embarrassment of having stubble when in a romantic or intimate situation with a partner. This draws on ideals of femininity that having smooth skin is more desirable or attractive.

Sophia's identity construction here, then, relies on assumptions of what it means to be a woman or girl. These assumptions are rooted in heteronormative expectations of gender. She refers to 'every girl' wanting to wear short or flesh-exposing outfits, including herself within

\footnotetext{
${ }^{4}$ My thanks to an anonymous reviewer for suggesting I look more closely at pauses in my analysis of these extracts.
} 
this category to position herself as typical. This is further bolstered by her shift in line 9 to the third person indefinite pronoun 'you' to describe the typical experience of many: 'when you...shave and stuff like that' (lines 9-10). In representing what 'you' do and experience (as well as what 'every girl' wants), Sophia constructs a sense of shared community practice and identity. Indeed, she assumes (in line with heteronormativity) that all women do shave, and do wish to shave. She presents shaving as an inevitable part of femininity, potentially excluding those who may not wish to shave their legs. By articulating her membership of this imagined community (Anderson 1983) of 'girls', and expressing her knowledge of what is typical practice, Sophia is also able to position herself as an expert. This is shown, for example, in her use of definitive modality (e.g. 'when your boobs start growing you are so happy', lines 14-15). It is apparent that Sophia's expertise is based on her experience, as she even shares information about aspects of her body that are a threat to her positive face ('it's horrible to admit but it's the truth', lines 20-21) - her embarrassment here is evident from her use of frequent pauses and her nervous laughter in line 20. Nonetheless, she includes these facts here, as they enable her to better present herself as an educator. In turn, this allows her to authorize her own legitimacy as a trans vlogger and present her experience as normal.

Sophia can also be seen to index a feminine identity through aspects of her language use in this extract. For example, in line 11 she swears ('I fucking hate that') but then immediately apologises for it (line 12). In this moment, she employs an apology as a politeness strategy, as well as an example of euphemism. These are both aspects of discourse which may be used in the construction of a stereotypically feminine identity (Holmes 1995). When taken in conjunction with the other aspects of femininity that she projects in this vlog, it is clear that Sophia is drawing on ideologies of womanhood that are entirely in line with heteronormative conceptualisations of femininity. Yet at the same time, she disrupts the essentialist idea of women being 'naturally' feminine by drawing attention to those aspects of her body which do not conform to this. In doing so, she presents a specifically trans form of femininity.

\subsection{Jay}

In contrast to the above two extracts, Jay's videos tend not to be explicitly about advice giving. Instead, he typically speaks about his personal experiences and feelings, using his YouTube channel largely to document his own transition. His subscribers also often ask questions via his YouTube page, however, and the extract below shows how he tends to respond to them. In the video, Jay addresses queries about his coming out experience, initially expressing discomfort about answering these questions (an unease indicated by relatively long pauses in lines 1-3):

\section{Extract 3}

1 but anyway this video. I'm going to make abou:t (.) how I knew that I was transgender uhm (1.5)

2 it seems to be something that a lot of people (1) have been either asking about. o:r (.) hinting

3 a:t o:r uhm (1) talking 'bout how to come out when they're at a young a:ge. like to their parents

4 and everything a:nd uhm (.) I'm finding it really hard to answer all of those questions? (.)

5 becau:se (.) I: went throu:gh (.) a sort of (.) more experimental process I didn't (.) just come

6 out. (.) one day. wake up and be like (.) oh I'm transgender I just found out what that is and

7 that's what I am. (.) because that's just not how I am as a person? I know some people (.) 
8 are like that and the moment they find out about transitioning. and about (.) uhm that there are

9 trans people uhm (1) they just know that that's them for sure and are completely adamant

10 about it? (.) but I: didn't go along that path. so I want to (.) sha:re my story about how come I

11 kinda figured it out. (.) uhm (.) because self-exploration (.) especially at young age is much more

12 important than a label. o:r uhm (1) just throwing yourself into something tha:t (.) doesn't

13 totally- that isn't totally explored yet? (.) so: basically (.) what what happened with me: was (.) I

14 always (.) had the hunch that I was. (.) that I was different.

Jay positions himself here as different to those who make quick decisions about their gender identity. This, in turn, allows him to state what he perceives to be best practice. Initially, he refers to those who act differently in a neutral way by acknowledging that variety exists ('I know some people...', line 7). However, he then goes on to polarise himself from those people ('that's just not how I am as a person', line 7), revealing his negative stance towards those that behave differently from him. He frames those who engage in less deliberation than him as foolish, with the adverbials 'just' and 'the moment' being used to indicate a sudden decision: 'the moment they find out about transitioning...they just know that that's for them' (lines 7-9). This allows Jay to position these hypothetical people as somewhat reckless, as 'throwing [themselves] into something that...isn't totally explored yet' (lines 12-13). In also characterising such people as being 'completely adamant' (line 11) about their trans status early on, a phrase which implies inflexibility or stubbornness, Jay positions them as oppositional to his own 'self-exploration' (line 11) and 'experimental process' (line 5).

Jay's use of a declarative in lines 11-12 ('self-exploration... is much more important than a label') is also authoritative. It suggests that he has the knowledge and experience to make such a claim, and indexes an educator or teacher role. This further enables him to position as illegitimate those who choose the 'path' (line 10) that he has framed as less important (or worthy) than his. It also implies that there is an ideal approach to take when first realising one's transgender status. On the one hand, this may be good advice: one should not rush into claiming an identity until completely sure about it. However, any young viewers who have already come out to their friends and family as transgender without undergoing therapy may feel excluded from this video, since Jay dismisses this practice in his categorisation of trans authenticity. This categorisation includes his own experience, of course, which he positions here as typical.

Later in the same vlog, Jay goes on to talk about his own coming out experience, talking firstly about his sexual desires. As Zimman (2012: 12) has argued, there is a prevalent assumption that, once a person transitions, they will experience only heterosexual desire. Though Jay does not explicitly claim this at any point, his explanation of how he discovered that he was transgender does contain certain heteronormative, essentialist ideologies. Though subtle, and though articulated specifically in relation to his own experience, these ideological assumptions could be influential given his fan-base. This point is considered in relation to the extract below, which begins with the first time he found a girl attractive: 


\section{Extract 4}

1 I was kinda like (1.5) woah (.) what is this? you know. uhm (.) and I was attracted to men at

2 the time. (.) I think it was more I was trying to fit into this sort of (.) box that is typical of a (.)

3 seventh grade $\{@$ female@ $\}<$ one minute omitted $>$ but then ninth grade hit (.) a:nd (.) I met this

4 girl who I was really attracted to. and I'd never been attracted to females I thought I was

5 heterosexual. (.) uhm (.) like a \{@heterosexual@\} female. (.) uh but the last boy I dated (.)

6 uhm (.) who I was actually in a band with for a while. he's uh (.) actually gay. (.) he came out as

7 being gay like six months after we stopped dating. (.) so that was kind of a little bit of a sign

8 there. $\{@$ uhm@\} (.) I found that I was attracted to more feminine guys anyway bu:t (1) anyway

9 so I became attracted to like this girl who was so open about her lesbian identity she was like (.)

10 it was high school. and (.) it really like took me aback so I realised I was attracted to females and

11 (.) uhm (1) because I was new at it and I hadn't had a girlfriend she kinda took the more (.)

12 masculine role? uhm (.) in the relationship (.) a:nd. part of me was like okay with that it was like

13 oh this is this is cool. (1.5) but then I realised like (2.0) as people started to stare at us as we

14 were like holding hands you know (.) down the street and everything. (.) and it was like a (.)

$15<$ makes scare quotes $>$ lesbian relationship (.) I was like (1.5) I feel I relate to her (.) as a male.

16 and (.) she doesn't really treat me like that and I'm not really acting like that but that's (.) how I

17 feel

Jay's narrative is produced in three stages, here. Firstly, he outlines his attempt to conform to heteronormative expectations of teenage girls. Secondly, he describes a boyfriend who was gay. Thirdly, he discusses his realisation that he was attracted to girls. Each of these subnarratives is an opportunity for Jay to articulate his normative male identity despite his past identification as a girl, which he does in terms of his essential masculinity and heterosexual desire. His initial representation of being 'attracted to men' (line 1) is explained via the retrospective construction 'I think it was more I was trying to fit into this sort of box that is typical of a seventh grade female' (lines 2-3). Here, he frames his apparent attraction not as desire per se but conformity to what was expected for a girl of age 12/13. He alludes here to what Eckert and McConnell-Ginet (2003: 26) call 'the heterosexual market', whereby children's interaction together forms a space for them to act out romantic relationships with 'the opposite sex' and thus learn how to conform to heteronormative gender roles. The construction 'I was attracted to men' is also placed in contrast to the girl that he met that he 'was really attracted to' (line 4). The adverb 'really' is emphasised here, allowing Jay to position his attraction to a girl as comparatively more genuine or intense than his attraction to men. This enables him to position his sexuality and his gender as inextricably linked, as he articulates his realisation that he was a boy as connected to his realisation that he desired girls. This reifies his identity as authentically male by drawing on heteronormative, essentialist assumptions that men desire women.

This continues with Jay's discussion of the last boy he dated. After introducing him within the narrative, Jay offers the information that the boy is gay (lines 6-7). In disclosing this, Jay draws attention to the fact that his relationship with the boy was not heteronormative despite Jay identifying at the time as female. Furthermore, Jay suggests that the boyfriend's sexuality 
was 'a little bit of a sign' (line 7). This may refer to the boyfriend's homosexuality being indicative of Jay's inherent maleness (i.e. that the boy could sense that Jay was trans), or it may position the boy as being more feminine due to his being gay (the kind of man Jay states in line 8 he was more attracted to). Both interpretations rely on heteronormative notions of inherent gender and gender inversion, and both allow Jay to legitimise his own identity as a male.

In the remainder of the extract, Jay's identity work concerns his desire for girls and, specifically, his realisation of his transgender identity due to entering a 'lesbian relationship' (line 15). He articulates his unease with this relationship in line 13, where longer pauses indicate his awkwardness in being interpreted as female, and contrasts this perceived lesbian relationship with his own desire to 'relate to her as a male' (line 15). The nouns 'lesbian' and 'male' are thus juxtaposed, allowing Jay to emphasise his non-female status. It is significant, though, that Jay does not prefix 'male' with 'straight' in order to produce an antonymic construction to the phrase 'lesbian [woman]'. By using only the term 'male' to describe how he wished to behave in the relationship with his girlfriend, he relies on heteronormative assumptions that men are heterosexual unless stated otherwise. Hegemonic ideologies associated with men and masculinity are therefore drawn on in this extract; Jay's inferences that men are naturally attracted to women and that gay men are more feminine are fundamentally heteronormative.

As an influential vlogger, Jay's account may be seen as more than just his own personal story: it is also an account of what is normal or expected. In this sense, as with Sophia's identity construction, such vlogs may be of central importance in the communication and spread of ideologies related to gender and sexuality.

\section{Discussion}

In the above analyses, I have argued that Sophia and Jay construct 'expert' personas as transgender vloggers. As Dame (2013: 40) suggests, this enables the articulation of an authentic trans self. It is clear that these videos are enormously important for the vloggers, then, as they allow them to gain self-fulfilment. They are also, however, of great consequence for the viewer in validating their own experiences and identities. As Rotman and Preece (2010: 320) argue, YouTube videos like these bring people with shared interests together and produce a virtual form of community. In this way, trans vloggers claim their own place within the world through their videos and also construct a sense of what is typical practice. All the while, their expert personas and popularity gives their narratives a degree of legitimacy, making their identity work potentially influential. The use of YouTube to chart one's transition also reveals that young people no longer rely solely on the resources created for them by educationalists, health workers, or the commercial media. In this sense, it is important to gain an understanding of how discourses are produced and circulated in this online context, to ensure that service providers or care givers are able to provide a level of support which is holistic and culturally informed.

For young, vulnerable people who may feel marginalised by society, vlogs can be used to learn what being transgender involves. Ostensibly, this includes finding out more about 
undergoing surgical or medical therapy (indeed, Jay regularly shows viewers the physical results of his treatment, such as his developing muscle definition and the healing of his mastectomy scars). I have argued here, though, that viewers may also learn a particular perspective on what is 'normal' for trans people. Many viewers will be able to challenge and resist the ideologies that are intertwined within vlogs such as these, but the amateur nature of the videos and highly personal content of the narratives seems to offer viewers a 'real' trans persona by which to interpret and measure their own identities. In particular, this is the case regarding gender and sexual desire in Jay and Sophia's videos. Though neither vlogger explicitly excludes non-heterosexual viewers, they claim their own authenticity as a woman or man by drawing an essential link between heterosexual desire and gender identity. In doing so, they reproduce many of the characteristics that Zimman (2012) argues make up the archetypal 'true transsexual', revealing the salience of this ideological identity category on young people's production of an authentically trans persona. This highlights the potential role of these vlogs in helping to circulate and reproduce transnormative ideologies.

As well as a notion of normative trans identity, Sophia and Jay take normalising stances towards particular transgender practices. Jay, for example, argues in Extract 3 that there is a correct way to come out to oneself and to others - by having therapy first. This renders illegitimate those who are unwilling or unable to embark upon therapy, yet Jay speaks from a position of privilege as a white, middle-class American who can afford such therapy and who has the ongoing support of his parents (he describes them as 'totally cool with [me being trans]' in an earlier vlog). This is an experience many of his viewers will not share due to the continued taboo and general lack of education around transgender issues. Sophia's identity work, on the other hand, is achieved by the adequation of her own experience with an imagined community of 'typical' women and girls, as shown by her claim in Extract 2 that 'every girl' wants to shave and wear feminine clothing (thus excluding those who do not). She also implies that all transgender people wish to live stealthily, or 'pass', positioning her own preferences as most authentic. This erases the possibility of (and subsequently others) those who identify in a non-binary way. Whilst the vlogs provide the sort of candid, first person narratives that most viewers could not find elsewhere, then, they also frame particular practices as more legitimate than others and play a role in producing an ideological discourse of what is 'normal' for transgender people. This provides a response to my initial question of whether a 'transnormative' discourse, informed by heteronormative ideologies, may be evident in the identity positioning of young transgender people. Though the cultural experience of being transgender differs enormously for women and men, it has indeed been shown in this paper that both of these vloggers draw on heteronormativity in their identity construction. As such, Sophia and Jay do index identities in line with the ideologically normative transgender person discussed by Zimman (2012).

I wish to stress that my critique is certainly not intended to admonish these two young people for bravely documenting their own transitions. However, my analysis does highlight the prevalence of somewhat constraining ideologies regarding gender and sexuality. Sophia and Jay have been shown to achieve their own identity work by positioning their identities as legitimate in line with broader ideological structures and expectations. Furthermore, they position their own experiences as typical in relation to others (reflecting Bucholtz and Hall's 
principle of Positionality as key to identity construction). To explore the salience of these transnormative discourses beyond their role in the construction of trans vlogger personas, further research into the identity work of transgender speakers is needed. Such work, particularly with young people, may reveal the true extent of the influence that vloggers like Jay and Sophia hold. It may also show the extent to which transnormative discourses may be challenged, reworked and resisted in a range of contexts.

\section{Transcription Conventions}

The method of transcription used here is adapted from Jefferson (2004).

- $\quad$ self- interruption or false start

(.) pause of less than 1 second

(2) timed pause

. $\quad$ end of intonation unit; falling intonation

? $\quad$ end of intonation unit; rising intonation

$<$ italics $>\quad$ transcriber comment

: lengthening of sound

\{@word@\} laughing quality

underline emphatic stress or increased amplitude

\section{References}

Anderson, Benedict. 1983. Imagined communities: Reflections on the origin and spread of nationalism. London: Verso Books.

Baker, Paul. 2014. Using corpora to analyze gender. London: Bloomsbury.

Borba, Rodrigo \& Ana Cristina Ostermann. 2007. Do bodies matter? Travestis' embodiment of (trans)gender identity through the manipulation of the Brazilian Portuguese grammatical gender system. Gender and Language 1(1): 131-47.

Bucholtz, Mary, \& Kira Hall. 2005. Identity and interaction: A sociocultural linguistic approach. Discourse Studies 7(4-5): 585-614.

Butler, Judith. 1990. Gender trouble: Feminism and the subversion of identity, London: Routledge.

Dame, Avery. 2013. "I'm your hero? Like me?" The role of 'expert' in the trans male vlog. Journal of Language and Sexuality 2(1): 40-69.

Eckert, Penelope \& Sally McConnell-Ginet. 2003. Language and Gender. Cambridge: Cambridge University Press.

Edelman, Elijah Adiv. 2009. The power of stealth: (In)visible sites of female-to-male transsexual resistance. In Ellen Lewin \& William Leap (eds.) Out in public: Reinventing lesbian/gay anthropology in a globalizing world, 164-79. Oxford: Wiley-Blackwell.

Fairclough, Norman. 1989. Language and power. New York: Longman. 
Grossman, Arnold H. \& Anthony R. D'Augelli. 2006. Transgender youth: Invisible and vulnerable. Journal of Homosexuality 51(1): 111-28.

Hall, Kira. 1997. "Go suck your husband's sugarcane!" Hijras and the use of sexual insult. In Anna Livia \& Kira Hall (eds.) Queerly phrased: Language, gender, and sexuality, 430-460. Oxford: Oxford University Press.

Hall, Kira \& Veronica O’Donovan. 1996. Shifting gender positions among Hindi-speaking Hijras. In Victoria Bergvall, Janet Bing \& Alice Freed (eds.) Rethinking language and gender research: Theory and practice, 228-66. London: Longman.

Holman, Catherine White \& Joshua M. Goldberg. 2006. Ethical, legal, and psychosocial issues in care of transgender adolescents. International Journal of Transgenderism 9(3-4): 95-110.

Holmes, Janet. 1995. Women, men and politeness. London: Longman.

Horak, Laura. 2014. Trans on YouTube: Intimacy, visibility, temporality. Transgender Studies Quarterly 1(4): 572-85.

Jefferson, Gail. 2004. Glossary of transcript symbols with an introduction. In Gene H. Lerner (ed.) Conversation analysis: Studies from the first generation, 13-31. Amsterdam: John Benjamins.

Jørgensen, Marianne \& Louise J. Phillips. 2002. Discourse analysis as theory and method. London: Sage Publications.

Jones, Lucy. 2012. Dyke/girl: Language and identities in a lesbian group. Basingstoke: Palgrave Macmillan.

Kulick, Don. 1996. Causing a commotion: Scandal as resistance among Brazilian travesti prostitutes. Anthropology Today 12(6): 3-7.

Morrish, Elizabeth \& Helen Sauntson. 2007. New perspectives on language and sexual identity. Basingstoke: Palgrave Macmillan.

Motschenbacher, Heiko \& Martin Stegu. 2013. Introduction: Queer linguistic approaches to discourse. Discourse and Society 24(5): 519-535.

Ochs, Eleanor. 1992. Indexing gender. In Alessandro Duranti \& Charles Goodwin (eds). Rethinking Context: Language as an Interactive Phenomenon, 335-58. Cambridge: Cambridge University Press.

Raun, Tobias. 2015. Video blogging as a vehicle of transformation: Exploring the intersection between trans identity and information technology. International Journal of Cultural Studies 18(3): 365-378. 
Rotman, Dana \& Jennifer Preece. 2010. The "WeTube" in YouTube: Creating an online community through video sharing. International Journal of Web Based Communities, 6(3): 317-333.

Silverstein, Michael. 2003. Indexical order and the dialectics of sociolinguistic life. Language and Communication, 23(3-4): 193-229.

Valentine, David. 2007. Imagining transgender: An ethnography of a category. Durham: Duke University Press.

YouTube. 2015. Statistics. https://www.youtube.com/yt/press/en-GB/statistics.html. Accessed $26^{\text {th }}$ August 2015.

Zimman, Lal. 2009. 'The other kind of coming out': Transgender people and the coming out narrative genre. Gender and Language 3(1): 53-80.

Zimman, Lal. 2012. Voices in transition: Testosterone, transmasculinity, and the gendered voice among female-to-male transgender people. Boulder, CO: University of Colorado at Boulder $\mathrm{PhD}$ dissertation.

Zimman, Lal. 2014. The discursive construction of sex: Remaking and reclaiming the gendered body in talk about genitals among trans men. In Lal Zimman, Jenny L. Davis \& Joshua Raclaw (eds.). Queer excursions: Rethinking binaries in language, gender, and sexuality, 13-34. Oxford: Oxford University Press. 